\title{
STUDY OF NEONATAL DEATH AND CAUSES IN ADMITTED NEONATES IN NEONATAL INTENSIVE CARE UNIT, GOVERNMENT MEDICAL COLLEGE, TEACHING HOSPITAL, SRIKAKULAM, A. P., INDIA
}

\author{
Soma Sekhara Rao Seepanaํ, Guna Sekhar Raju S.2
}

${ }_{1}^{1}$ Associate Professor, Department of Paediatrics, Government Medical College, Srikakulam, Andhra Pradesh, India.

${ }^{2}$ Assistant Professor, Department of Paediatrics, Government Medical College, Srikakulam, Andhra Pradesh, India.

\section{ABSTRACT}

\section{BACKGROUND}

Neonatal death is loss of the newborn within the first twenty-eight days of life. Neonatal deaths and stillbirths are still a problem especially in developing countries like India. However, it remains an untold grief for the mother. Because of the magnitude of the problem and its direct linkage with the quality of health services during antenatal, natal care of the mother and postnatal care of the neonates, neonatal mortality rate is one of the key indicators of the health status of any country. Therefore, this study will guide us to take appropriate action to reduce neonatal death through gathering information about neonatal death and its possible causes in the area studied. We wanted to assess neonatal deaths and their causes in neonatal intensive care unit of Government Medical College, Srikakulam, Andhra Pradesh, India.

\section{METHODS}

This is an institution based cross sectional study done from April 2014 to March 2019. The nominal register of admitted neonates was studied by using collected data. Data was analysed manually and presented in text, percentages, frequencies and tables.

\section{RESULTS}

As per Neonatal Intensive Care Unit nominal registers, 7238 neonates were admitted in the last five years. Out of 7236 neonates admitted 936 died due to different causes. Out of the 936 neonates, 529 were male and 406 were females. 212 were delivered prematurely, 74 were admitted with diagnosis of sepsis and 143 were admitted due to low birth weight, 209 were birth asphyxia, 91 were hypoxic ischemic encephalopathy, 67 were respiratory distress, 70 were meconium aspiration syndrome, 31 were congenital malformation and others.

\section{CONCLUSIONS}

Out of 936 death of neonates which occurred in Neonatal Intensive Care Unit of Government Medical College, Srikakulam, Andhra Pradesh, India, prematurity, sepsis, low birth weight and asphyxia were the foremost causes. Health care providers working on maternal health care service delivery and NICU should be emphasize on educating and counselling about prevention of infection and asphyxia.

\section{KEY WORDS}

Neonate, Asphyxia, Death, Birth, Causes, Infection, Mortality

HOW TO CITE THIS ARTICLE: Seepana SSR, Raju GSS. Study of neonatal death and causes in admitted neonates in neonatal intensive care unit, government medical college, teaching hospital, Srikakulam, A. P., India. J. Evolution Med. Dent. Sci. 2019;8(28): 2279-2282, DOI: $10.14260 /$ jemds/2019/499

\section{BACKGROUND}

Globally 2.5 million children died in the first month of life in 2017 approximately 7,000 newborn deaths every day with about 1 million dying on the first day and close to 1 million dying within the next 6 days. ${ }^{1} \mathrm{~A}$ child's risk of dying is highest in the first 28 days of life, during the neonatal period. In 2017, $47 \%$ of all under five child deaths were among newborn infants up from $40 \%$ in $1990 .{ }^{2}$ Globally an estimated 13 million babies are born before 37 completed weeks of gestation.

'Financial or Other Competing Interest': None.

Submission 12-04-2019, Peer Review 27-06-2019,

Acceptance 05-07-2019, Published 15-07-2019.

Corresponding Author:

Soma Sekhara Rao Seepana,

Plot No. 13, Opposite R and B Office,

Prasham Gardens,

One Way Traffic Road,

Srikakulam-532001,

Andhra Pradesh, India.

E-mail: somasekharseepana@gmail.com

DOI: $10.14260 /$ jemds $/ 2019 / 499$

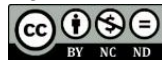

This figure is high among middle- and low-income countries. ${ }^{3}$ LBW is the result of either intrauterine growth retardation or premature birth. LBW is the main cause of fetal and neonatal morbidity and mortality. Later in life, it can be highly associated with chronic diseases and inhibited growth and development including poor academic achievement. ${ }^{4}$ Multiple gestation, mothers' body composition during conception, maternal short stature, residing at high altitudes, maternal nutrition during pregnancy including life style (substance or drug abuse) and medical disorders during pregnancy including hypertensive disorders were risk factors of LBW babies. Additionally, mothers with low socio-economic status are prone to infections from poor nutrition, thus birth weight will decrease. ${ }^{5}$ Globally, prematurity (29\%), infections (29\%), asphyxia (23\%), congenital malformations (8\%), and other $(11 \%)$ are important causes of neonatal death in lowincome country while prematurity and malformation contribute in developed countries. ${ }^{6}$ About 44 percent of these childhood deaths occur within the first 28 days of life, thus increasingly accounting for a larger proportion of the under five deaths. 7 Moreover, 79 percent of neonatal deaths occur during early neonatal period (0-6 days) of which 41 percent is in the first 24 hours of birth where as 21 percent happen in 
late neonatal period (7-28 days). ${ }^{8}$ In India, 26 million babies are born every year, and 1.2 million die in the first four weeks of life, which accounts for a quarter of global neonatal deaths. India thus faces the biggest newborn health challenge of any country in the world. ${ }^{9}$ Antenatal care (ANC) visits are important for maternal and fetus health. Pregnant mothers who attended less than four ANC visits double their risk of delivering LBW babies compared to those visiting four or more times. ${ }^{10,11}$ The neonatal period begins with birth and ends after 28 days of birth. Neonatal deaths may be subdivided into early neonatal deaths occurring during the first seven days of life (06 days), and late neonatal deaths occurring after the seventh day but before the 28th day of life (7-27 days). ${ }^{12}$ Neonatal mortality rate is number of deaths among children below 28 days of age in a year per number of live births in the same year and it is usually expressed per 1000 live births. ${ }^{13}$ The common cause of neonatal mortality in India are asphyxia, prematurity and low birth weight, sepsis, congenital abnormalities, variety of surgical problems. Improved level of newborn care can bring down the mortality rates. ${ }^{14}$ Because of the high magnitude of the problem and its direct linkage with the quality of health service during pregnancy, peripartum and in the neonatal period. Neonatal mortality rate (NMR) are used as an important indicators of the health status of a country. ${ }^{15}$ Children who die within the first 28 days of birth suffer from conditions and diseases associated with lack of quality care at birth or skilled care and treatment immediately after birth and in the first days of life. Women who receive midwife-led continuity of care provided by professional midwives, educated and regulated to internationals standards, are $16 \%$ less likely to lose their baby and $24 \%$ less likely to experience preterm birth. Infant mortality rate Andhra Pradesh come down from 8.67 lakh in 2016 to 8.02 lakh in 2017. In 2016, India's infant mortality rate was 44 per 1,000 live births. In 2017, sex-specific under-five mortality rate was 39 in 1,000 for male and 40 in 1,000 for females as of Sep 18, 2018. In this study, we present overall percentage and pattern of neonatal deaths in a tertiary hospital of a developing country. In order to prevent the neonatal mortality, it is important to know the causes and predisposing.

\section{METHODS}

\section{Study Area}

Government Medical College, Teaching Hospital, Srikakulam; Andhra Pradesh, India.

\section{Study Design and Study Period}

Institution based cross sectional study was done from April 2014 to March 2019.

\section{Study Population}

All neonates admitted in NICU Government Medical College, Teaching Hospital, Srikakulam; Andhra Pradesh, India. Were included in the study.

\section{Sample Size}

All cards of admitted neonates to NICU Government Medical College, Teaching Hospital, Srikakulam; Andhra Pradesh, India Total admissions of new born were 7238, deaths were 936.

\section{Sampling Procedure}

The nominal register book of admitted neonates in NICU taken according to the objectives needed data were recorded by using the check lists.

\section{Inclusion and Exclusion Criteria}

All neonates born and admitted to intensive neonatal care unit of Government Medical College, Teaching Hospital, Srikakulam, Andhra Pradesh, India whose age less than 28 days were included in this study.

\section{Data Collection Tools and Analysis}

The observational check list that answer the objectives of the study was prepared and recorded from the nominal register book of admitted neonates in NICU Government Medical College, Teaching Hospital, Srikakulam; Andhra Pradesh, India. Before the actual data collection, the nominal register book was checked all available data present or not.

\section{Operational Definition- Neonatal Mortality Rate}

Number of newborn deaths less than 28 days of age per one thousand live births per year.

\section{Neonatal Death Causes}

I mean that any medical or other cause which will be diagnosed in this study.

\section{Congenital Malformation}

Body deformity or deformities from the birth believed to have impact on health of the baby.

\section{Hypoglycaemia}

A measure of low blood glucose $(<40 \mathrm{mg} / \mathrm{dL})$ that was diagnosed and recorded on charts by professionals on admission.

\section{Hypothermia}

Any low body temperature measurement $\left(<36^{\circ} \mathrm{C}\right)$ diagnosed and recorded on charts during admission of neonates.

\section{Premature}

Any viable neonate before term $(<37$ weeks of gestation) that was already diagnosed by professionals in charge on admission of neonate to neonatal intensive care units.

\section{Sepsis}

Record of infection or sepsis diagnosed either clinically or with culture by professionals during admission of the neonate and as possible causes of death and designated or recorded on chart.

\section{RESULTS}

Neonatal Deaths

According to records from Neonatal intensive Care Unit 7238 neonates were admitted in the last five years 936 were dead due to different reasons. Among death 529 were male and 407 were females. 883 deaths occurred within 7 days out of those within 24 hours 275 and 48 hours 511 and 7 days 97 and 53 deaths between 28 days (Table 1 ). 


\begin{tabular}{|c|c|c|c|}
\hline \multirow[t]{2}{*}{ Age Category } & \multicolumn{2}{|c|}{ Sex } & \multirow[t]{2}{*}{ Total Death } \\
\hline & Male & Female & \\
\hline$<24$ hours & 153 & 122 & 275 \\
\hline 24 to 48 hours & 292 & 219 & 511 \\
\hline 48 hours to 7 days & 54 & 43 & 97 \\
\hline Between $7-28$ days & 32 & 21 & 53 \\
\hline Total & 529 & 407 & 936 \\
\hline \multicolumn{4}{|c|}{$\begin{array}{c}\text { Table 1. Causes of Death Among Neonates Admitted in } \\
\text { Government Medical College, Teaching Hospital, Srikakulam, } \\
\text { Andhra Pradesh, India }\end{array}$} \\
\hline
\end{tabular}

\begin{tabular}{|c|c|c|c|c|c|}
\hline \multirow{2}{*}{$\begin{array}{l}\text { Sl. } \\
\text { No. }\end{array}$} & \multirow{2}{*}{$\begin{array}{c}\text { Cause of Admission } \\
\text { and Death }\end{array}$} & \multicolumn{3}{|c|}{ Frequency $\mathrm{N}=936$} & \multirow[b]{2}{*}{ Percentage } \\
\hline & & Male & Female & Total & \\
\hline 1 & Prematurity & 126 & 86 & 212 & 22.65 \\
\hline 2 & Birth Asphyxia/HIE & 169 & 131 & 300 & 32.05 \\
\hline 3 & Low Birth weight & 61 & 41 & 102 & 10.91 \\
\hline 4 & ELBW & 22 & 19 & 41 & 4.38 \\
\hline 5 & Sepsis & 41 & 33 & 74 & 7.91 \\
\hline 6 & Respiratory Distress & 41 & 26 & 67 & 7.16 \\
\hline 7 & $\begin{array}{l}\text { Meconium Aspiration } \\
\text { syndrome }\end{array}$ & 34 & 36 & 70 & 7.47 \\
\hline 8 & Congenital Malformation & 12 & 19 & 31 & 3.31 \\
\hline 9 & Neonatal Jaundice & 2 & 0 & 2 & 0.21 \\
\hline 10 & Others & 20 & 17 & 37 & 3.95 \\
\hline \multicolumn{6}{|c|}{$\begin{array}{l}\text { Table 2. Causes of Death Among Neonates Admitted in Government } \\
\text { Medical College, Teaching Hospital, Srikakulam; Andhra Pradesh, } \\
\text { India }\end{array}$} \\
\hline
\end{tabular}

\begin{tabular}{|c|c|c|c|c|c|c|}
\hline \multirow[t]{3}{*}{ Disease } & \multicolumn{4}{|c|}{ Out Come } & \multicolumn{2}{|c|}{ Total 6640} \\
\hline & \multicolumn{2}{|c|}{ Discharged } & \multicolumn{2}{|c|}{ Expired } & \multirow{2}{*}{$\mathbf{N}$} & \multirow{2}{*}{$\%$} \\
\hline & $\mathbf{N}$ & $\%$ & $\mathbf{N}$ & $\%$ & & \\
\hline Septicaemia & 846 & 91.96 & 74 & 8.04 & 920 & 100 \\
\hline HIE & 745 & 89.11 & 91 & 10.89 & 836 & 100 \\
\hline Birth Asphyxia/HIE & 1368 & 82.01 & 300 & 17.99 & 1668 & 100 \\
\hline Neonatal Jaundice (NNJ) & 695 & \begin{tabular}{ll|}
99.8 \\
\end{tabular} & 5 & 0.02 & 700 & 100 \\
\hline $\begin{array}{l}\text { Transient Tachypnoea of } \\
\text { Neonates (TTN) }\end{array}$ & 605 & 99.83 & 1 & 0.17 & 606 & 100 \\
\hline $\begin{array}{c}\text { Meconium Aspiration } \\
\text { Syndrome (MAS) }\end{array}$ & 378 & 84.36 & 70 & 15.64 & 448 & 100 \\
\hline Prematurity & 276 & 56.56 & 212 & 43.44 & 488 & 100 \\
\hline LBW & 309 & 75.18 & 102 & 24.82 & 411 & 100 \\
\hline others & 207 & 85.89 & 34 & 14.11 & 241 & 100 \\
\hline $\begin{array}{l}\text { Respiratory Distress } \\
\text { Syndrome (RDS) } \\
\end{array}$ & 91 & 57.96 & 66 & 42.04 & 157 & 100 \\
\hline IUGR & 154 & 91.67 & 14 & 8.33 & 168 & 100 \\
\hline Congenital Anomalies & 40 & 49.38 & 41 & 50.62 & 81 & 100 \\
\hline Meningitis & 55 & 88.71 & $\begin{array}{lll}7 & & \\
\end{array}$ & 11.29 & 62 & 100 \\
\hline Seizure Disorder & 27 & 81.81 & 6 & 18.29 & 33 & 100 \\
\hline ELBW & 41 & 56.94 & 31 & 43.06 & 72 & 100 \\
\hline Pneumonia & 19 & 90.48 & 3 & 9.52 & 21 & 100 \\
\hline Hypoglycaemia & 8 & 100 & 0 & 0 & 8 & 100 \\
\hline shock & 0 & 0 & 3 & 0 & 3 & 100 \\
\hline ARF & 3 & 75 & 1 & 25 & 4 & 100 \\
\hline Extreme preterm & 2 & 66.66 & 1 & 33.34 & 3 & 100 \\
\hline Diarrhoea & 2 & & 0 & & 2 & 100 \\
\hline DIC & 0 & & 0 & & 0 & 100 \\
\hline Hyperthermia & 1 & & 0 & & 1 & 100 \\
\hline & 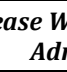 & & $a$ & & & 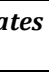 \\
\hline
\end{tabular}

\section{Cause of Neonatal Deaths}

Out of all neonatal deaths $212(22.65 \%)$ of them were delivered prematurely, 74 (7.91\%) were those admitted for diagnosis of sepsis, $102(0.91 \%)$ were those admitted due to low birth weight (LBW), 41 (4.38\%) were extremely low birth weight (ELBW), 31 (3.31\%) Congenital malformation cause for neonatal death, 67(7.16\%)were respiratory distress (RD), $300(32.05 \%)$ were birth asphyxia (BA)/hypoxic ischemic encephalopathy (HIE), 70 (7.47\%) meconium aspiration syndrome (MAS), least cause of death in this study is neonatal jaundice two case out of 936 deaths while 37 (3.95\%) deaths are due to other. (Table 2)

The data was analysed for the case fatality rate and it was observed that out of Discharged and Expired neonates(6640) it was observed that case fatality rate was more in MAS (15.64\%), Congenital Anomalies (50.62\%), Prematurity (43.44\%), Birth Asphyxia/HIE (17.99\%), RDS (42.04\%),
Septicaemia (8.04\%), LBW (24.83\%), TTN (0.17\%) and Pneumonia (9.52\%), Meningitis (11.9\%) (Table 3).

\section{DISCUSSION}

Out of 7238 admitted cases in neonatal care unit 936 (12.93\%) of them are reported to be dead. Our study revealed that the survival of a neonate in the neonatal unit depended on the birth weight, 5-minute Apgar score, place of delivery, gestational age and discharge diagnosis. ${ }^{16}$ Although different researches have documented evidence to show higher mortality percentages in male than female infants. ${ }^{17,18} \mathrm{We}$ found no significant difference in the mortality of males and females. However, the reasons for such contrast result could not be explained from the result. The overall mortality at the neonatal unit was $12.93 \%$ However, percentage of mortality among newborns referred to the facility still remains very high. This is because most newborns referred to NICU GMC Srikakulam are usually very sick and require specialist care that is not provided by primary health facilities. Although gestational age asphyxia were a significant risk factor, it was only significant among newborns admitted NICU GMC Srikakulam asphyxia and Pre-term birth was associated with a higher risk of death and higher mortality percentage more than the overall percentage. Pre-term newborns require special care from skilled workers to improve their chances of survival (9) to (19). The major conditions associated with neonatal death were birth asphyxia, infections, respiratory distress, prematurity, sepsis, infections and other neonatal conditions. Among these neonatal conditions, birth asphyxia recorded the highest death rate. Clean birth practices have shown to significantly reduce neonatal mortality. Basic wellknown hygienic practices such as hand washing and maintaining a clean environment are poorly observed. ${ }^{19}$ In this present study birth weight was a major risk factor of neonatal deaths.

Our study showed that case fatality out of 7238 admitted discharged were 6640, rate was more in RDS (42.04\%), Prematurity (43.44\%) Birth Asphyxia (25.12\%), LBW (24.83\%), MAS (15.64\%), HIE (10.89\%), Congenital Anomalies (50.62\%), Septicaemia (8.04\%), TTN (0.17\%) and Pneumonia (9.52\%), Meningitis (11.9\%). The most common cause of neonatal mortality was prematurity in our study which is similar to studies conducted by Seyal, et al.20 Nahar, et al. ${ }^{21}$ Narayan. ${ }^{22}$ Prasad, et al. ${ }^{23}$ and Ali, et al. ${ }^{24}$ Including the all admitted neonates in last five years since the service of NICU started in the hospital is the strength of this study. The study was only depending on record review which is subjected for incompleteness of record which enhances bias.

\section{CONCLUSIONS}

936 death of neonates occurred in Neonatal Intensive care unit of Government Medical College, Teaching Hospital, Srikakulam, Andhra Pradesh, India. The higher percentage of deaths occurred within 7 days of birth. Prematurity, sepsis, low birth weight and asphyxia accounted for higher percentage among the causes.

\section{REFERENCES}

[1] WHO (2016) Global strategy for women's, children's and adolescents' health (2016-2030). 
[2] Bryce J, Boschi-Pinto C, Shibuya K, et al. WHO estimates of the causes of death in children. Lancet 2005;365(9465):1147-52.

[3] Lawn JE, Gravett MG, Nunes TM, et al. Global report on preterm birth and stillbirth (1 of 7): definitions, description of the burden and opportunities to improve data. BMC Pregnancy Childbirth 2010;10(Suppl 1):S1.

[4] Barker DJP. Fetal and infant origins of adult disease. London: British Medical Journal Books 1992.

[5] Consultation WT. Towards the development of a strategy for promoting optimal fetal growth. Report of a meeting (draft). Geneva: World Health Organisation 2004.

[6] Black RE, Cousens S, Johnson HL, et al. Global, regional and national causes of child mortality in 2008: a systematic analysis. Lancet 2010;375(9730):1969-87.

[7] Blackman JA. Neonatal intensive care. Is it worth it? Ped Clin North Am 1991;38(6):1497-1511.

[8] Narang A, Kiran PS, Kumar P. Cost of neonatal intensive care in a tertiary care center. Indian Pediatrics 2005;42(10):989-97.

[9] National Neonatology Forum. Washington (DC) National Neonatology Forum and Save the Children US 2004. The state of India's newborns.

[10] Mohanty C, Prasad R, Reddy A, et al. Maternal anthropometry as predictors of low birth weight. J Trop Pediatr 2005;52(1):24-9.

[11] Janjua ZN, Delzell E, Larson RR. In: Public Health Nutrition edr. Determinants of low birth weight in Urban Pakistan. Birmingham, AL: UAB.EDU 2008.

[12] Kolola T, Ekubay M, Tesfa E, et al. Determinants of neonatal mortality in North Shoa Zone, Amhara regional state, Ethiopia. PLoS One 2016;11(10):e0164472.

[13] Edmond KM, Zandoh C, Quigley MA, et al. Delayed breastfeeding initiation increases risk of neonatal mortality. Pediatrics 2006;117(3):e380-e6.

[14] Jain S, Bhakoo ON, Singh M. Neonatal Monitoring, Recommendations and Proceedings of the Seminar 1990. Indore: Chathram Hospital \& Research Center, 1990: p. 6-17.
[15] Berhan Y, Berhan A. Perinatal mortality trends in Ethiopia. Ethiop J Health Sci 2014;(Suppl 24):29-40.

[16] Welbeck J, Biritwum RB, Mensah G. Factors affecting the survival of the "at risk" newborn at Korle $\mathrm{Bu}$ Teaching Hospital, Accra, Ghana. West Afr J Med 2003;22(1):55-8.

[17] Jehan I, Harris H, Salat S, et al. Neonatal mortality, risk factors and causes: a prospective population-based cohort study in urban Pakistan. Bull World Health Organ 2009;87(2):130-8.

[18] Anand K, Kant S, Kumar G, et al. Neonatal morbidity and mortality of sick newborns admitted in a teaching hospital of Uttarakhand. CHRISMED J Heal Res 2014;1(4):247-53.

[19] Lawn JE, Davidge R, Paul VK, et al. Born too soon: care for the pre-term baby. Reprod Health 2013;10(Suppl 1):S5.

[20] Seyal T, Husnain F, Anwar A. Audit of neonatal morbidity and mortality at neonatal unit of Sir Gangaram Hospital Lahore. Annals King Edward Med University 2011;17(1):9-13.

[21] Nahar J, Zabeen B, Akhter S, et al. Neonatal morbidity and mortality pattern in the special care baby unit of Birdem. Ibrahim Med Coll J 2007;1:1-4.

[22] Narayan R. A study of pattern of admissions and outcome in a neonatal intensive care unit at high altitude. Sri Lanka Journal of Child Health 2012;41(2):79-81.

[23] Prasad V, Singh N. Causes of morbidity and mortality in neonates admitted in Government Medical College HaldwaniinKumaon Region Uttarakhand) India. Journal of Pharmaceutical and Biomedical Sciences 2011;8:1-4.

[24] Ali SR, Ahmed S, Lohana H. Disease patterns and outcomes of neonatal admissions at a secondary care hospital in Pakistan. Sultan Qaboos University Med J 2013;13(3):424-8. 